\title{
Micrographia associated with a parietal lobe lesion in multiple sclerosis
}

\author{
N J Scolding, A J Lees
}

\begin{abstract}
The occurrence of micrographia in a 52 year old women two years after an isolated episode of painful sensory disturbance led to the diagnosis of multiple sclerosis. Her handwriting returned to normal after a course of intravenous methylprednisolone. Previous reports of movement disorders occurring in the context of multiple sclerosis are briefly reviewed. The finding on MRI studies of an enhancing lesion in the dominant parietal white matter supports Kinnier Wilson's suggestion that the anatomical origin of micrographia lies in the cerebral hemisphere rather than the corpus striatum.
\end{abstract}

$(\mathcal{A}$ Neurol Neurosurg Psychiatry 1994;57:739-741)

Neurology and

Neurosurgery, Queen

Square, London,

WC1N 3BG, UK

N J Scolding

A J Lees

Correspondence to:

Dr Lees

Received 13 January 1993

and in final revised form

10 May 1993 .

Accepted 27 May 1993 monly than sustained symptoms. We describe the case of a 52 year old woman, in whom the onset of micrographia two years after a spontaneously resolving painful sensory disturbance led to further investigations that confirmed the diagnosis of multiple sclerosis. Treatment with intravenous steroids was accompanied by a rapid resolution of her micrographia.

\section{Case report}

A 50 year old right handed woman developed a superficial burning sensation in her right anterior thigh spreading to the suprapubic area, together with hyperpathia, two months after an oopherectomy for benign ovarian cysts. This was unaccompanied by any motor or sphincter symptoms, and there were no objective abnormalities on examination. Investigations, including blood count, erythrocyte sedimentation rate, glucose, liver function, protein electrophoresis, ultrasound scan of pelvis, and MRI of the spinal cord were all normal, and her symptoms resolved spontaneously after three months.

Two years later, two months after minor surgery for a Meibomian cyst, she noticed an abrupt change in her handwriting. Her script had become smaller and less clear; the act of writing had become laborious. Other activities requiring fine finger control, including sewing, tying parcels and peeling vegetables were unaffected, but she had noticed a slight deterioration in the speed and accuracy of her right hand using a word processor keyboard.

At this time, general physical examination was unremarkable, and there were no neurological abnormalities in the cranial nerves or in the lower limbs. Power, tone and tendon reflexes, and sensation were all normal. Language function was entirely normal, as were other tests of higher mental function. Her handwriting was slow and small, however (fig 1), with a tendency to decrease further in size as she continued writing; she was unable to increase the size to command. Copying tests revealed no constructional apraxia and there were no other visuospatial abnormalities. There was very slight impairment of rapid alternating movement of the right hand and finger. Tests of mimicking, mime, and object use revealed no apraxia. Facial expression was normal, there was no glabellar tap response, no bradykinesia, and her gait was normal.

Routine blood tests were again normal or 
Figure 2 T1-weighted $M R I$ head scan during the episode of micrographia. The largest lesion, in the left parietal white matter, is shown in coronal section, exhibiting considerable rim enhancement after gadolinium-DTPA injection. There were numerous other high signal intensity lesions on T2weighted images and corresponding low signal lesions on T1-weighted scans situated in the white matter of both cerebral hemispheres, particularly in the periventricular areas (not shown).

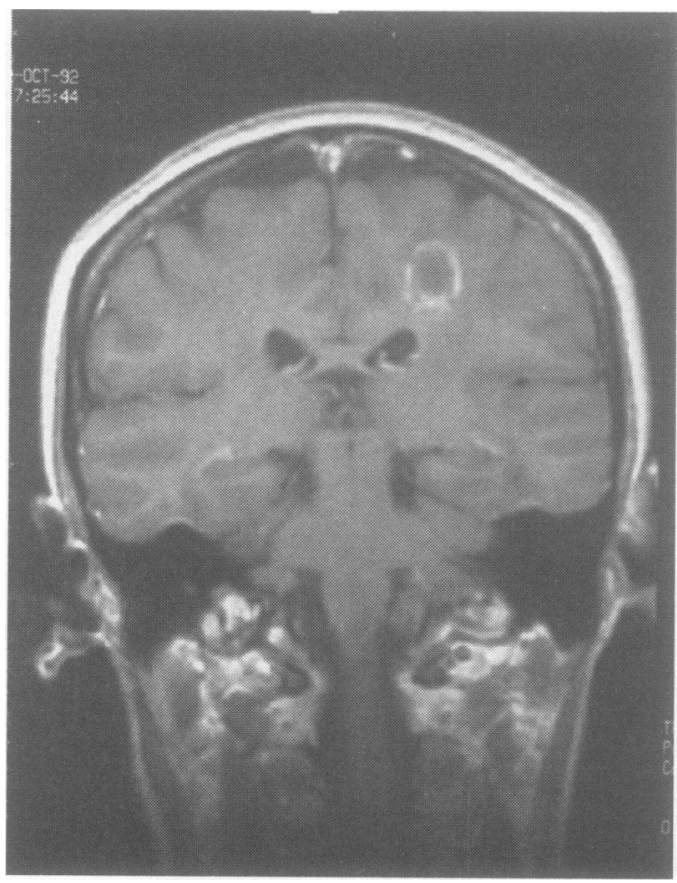

negative, including autoimmune and treponemal serological tests. Visual, auditory, and somatosensory evoked potentials (from both upper limbs) were also normal. An MRI scan of her head showed multiple T2 high, T1 low signal lesions in the white matter of both cerebral hemispheres, however, particularly in the periventricular areas. The largest lesion, in the left parietal white matter, showed rim enhancement (fig 2); it did not involve the basal ganglia. None of the lesions exhibited a mass effect, and the appearances were interpreted as being strongly suggestive of multiple sclerosis.

A course of intravenous methyprednisolone ( $1 \mathrm{~g}$ daily for three days) was associated temporally with a good improvement in the size and fluency of her handwriting (fig 1 (bottom)); this improvement has thus far (now six months after her original symptoms) been maintained. Furthermore, repeated examinations have consistently continued to fail to reveal the emergence of any parkinsonian signs.

\section{Discussion}

The clinical picture of an episode of painful sensory disturbance spontaneously resolving over two to three months, followed by an episode of motor disturbance that resolved after a course of high dose intravenous steroids, is highly suggestive of multiple sclerosis, a diagnosis strongly supported by the MRI abnormalities.

Extrapyramidal movement disorders are unusual in multiple sclerosis ${ }^{12}$; of these, negative phenomena are rarer still, although paroxysmal akinesia is reported. ${ }^{1}$ A small number of cases with pill rolling tremor have been described, ${ }^{34}$ but non-paroxysmal akinesia and extrapyramidal rigidity are rare. Mao et $a l^{2}$ reported two cases with tremor, bradykinesia, hypomimia, and rigidity, one of whom was treated (unsuccessfully) with intravenous steroids, and Vieregge et $a l^{5}$ also reported two cases of parkinsonism associated with multiple sclerosis; both had hyperintense lesions on spin-echo MRI that involved the basal ganglia, and both made a significant response to intravenous steroid treatment.

Our case was notable for the occurrence of micrographia without other features of parkinsonism. Micrographia was first described by Pick in $1903^{6}$; the association with parkinson's disease was soon recognised, ${ }^{7}$ and has since been accepted as a feature of diagnostic significance. ${ }^{8}$ Kinnier Wilson described cases of micrographia in cerebral syphilis and in arteriosclerosis, however, with subsequent postmortem studies revealing the absence of involvement of the corpus striatum. ${ }^{9} \mathrm{He}$ also cited cases of severe postencephalitic parkinsonism with profound immobility and rigidity and yet normal handwriting, and of severe micrographia in a female with otherwise very minor parkinsonian symptoms.

McClennan et al have more recently confirmed that "micrographia is totally separable from tremor and rigidity", basing their conclusion on a detailed study of 95 patients with micrographia associated with parkinsonism. ${ }^{10}$ They found a lack of correlation between micrographia and the side, severity, and duration of classical parkinsonian features; micrographia often preceded other manifestations by as much as three to four years, and exhibited a very variable response to L-dopa treatment, by contrast with its more predictable beneficial effect on other symptoms and signs.

Court described an association of depression with micrographia, ${ }^{11}$ although McClennan's group found that "elevation or depression of mood...did not...have much effect on micrographia"-which they also noted did not improve with antidepressant treatment. ${ }^{10}$

Although McClennan et al do not speculate on the anatomical substrate for micrographia, Kinnier Wilson concluded that abnormalities in the cerebral cortex were much more likely to underly micrographia than disorders in the corpus striatum. The matter remains unresolved: Martinez Vila et al recently reported a patient with isolated micrographia associated with a lenticular haematoma. ${ }^{12}$ Our case supports Kinnier Wilson's suggestion, as MRI scanning revealed no abnormality in the basal ganglia but a large lesion in the dominant parietal white matter. The lesion enhanced with gadolinium so that it is likely to reflect active disease $^{13}$ and to be responsible for her symptoms.

1 Mathews WB, ed. McAlpine's multiple sclerosis. 2nd ed. London: Churchill Livingstone, 1991:70.

2 Mao CC, Gancher ST, Herndon RM. Movement disorders in multiple sclerosis. Mov Disord 1988:3:109-16.

3 Fog $T$, Linnemann $F$. The course of multiple sclerosis. Acta Neurol Scand 1970;47(suppl):1-175.

4 McAlpine D, Lumsden CE, Acheson ED. Multiple sclerosis: a reappraisal. Baltimore: Williams and Wilkins, 1972:177-8. 
5 Vieregge $\mathrm{P}$, Klosterman $\mathrm{W}$, Bruckman $\mathrm{H}$. Parkinsonism in multiple sclerosis. Mov Disord 1992;7:381-2.

6 Pick A. Ueber eine eigentumliche Schreibstorung, Mikrographie, in Folge cerebraler Erkrankung. Prag Med Wschr 1903;28:1-4.

7 Froment MF. De la micrographie dans les etats Parkinsoniens postencephalitiques et des conditions qui Parkinsoniens postencephalitiques et des conditions qui
sont susceptibles de la modifier. Rev Neurol (Paris) sont susceptibles

8 Riley D, Lang AE. Parkinson's Disease. In: Bradley WG, Daroff RB, Fenichel GM, Marsden CD, eds. Neurology in clinical practice, vol 2. Boston: ButterworthHeinemann, 1989;1566-7

9 Kinnier Wilson SA. The Croonian Lectures on some disorders of motility and of muscle tone, with special reference to the corpus striatum. Lancet $1925 ; \mathbf{i i}: 1-10$.

10 McLennan JE, Nakano K, Tyler HR, Schwab RS. Micrographia in Parkinson's disease. F Neurol Sci 1972; 15:141-52.

11 Court JH. A longitudinal study of psychomotor function in acute psychiatric patients. $\mathrm{Br} \mathcal{F}$ Med Psychol 1964; 37:167-73.

12 Martinez Vila E, Artieda J, Obeso JA. Micrographia secondary to lenticular haematoma. $\mathcal{F}$ Neurol Neurosurg Psychiatry 1988;51:1353.

13 McDonald WI, Barnes D. Lessons from magnetic resonance imaging in multiple sclerosis. Trends Neurosci 1989;12:376-9.

\section{NEUROLOGY IN LITERATURE}

\section{Amnesia}

Amnesia that includes the loss of memory for personal details seldom causes the neurologist diagnostic difficulty. The condition is not related to organic brain disease and it is perhaps surprising that novelists continue to regard it as such. Sometimes, as for example with Saki, the problem is pursued for its comic possibilities. The whole of Rebecca West's novel, The return of the soldier, is constructed around the premise of memory loss for personal affairs. Dickens's characterisation is curious in that Dr Manette appears to retain some insight into his behaviour; one would almost consider the problem to be one of malingering, though clearly that was never Dickens's intention.

Charles Dickens, 1859, A tale of two cities

Miss Pross, with a terrified face, was at his ear. "O me, O me, all is lost!" cried she, wringing her hands. "What is to be told to Ladybird? He doesn't know me, and is making shoes!" . . "Doctor Manette. My dear friend, Doctor Manette!" The Doctor looked at him for a moment-half enquiringly, half as if he were angry at being spoken to-and bent over his work again.

So far as it was possible to comprehend him without overstepping those delicate and gradual approaches which Mr. Lorry felt to be the only safe advance, he at first supposed that his daughter's marriage had taken place yesterday. An incidental allusion, purposely thrown out, to the day of the week, and the day of the month, set him thinking and counting, and evidently made him uneasy. In all other respects, however, he was so composedly himself, that Mr. Lorry determined to have the aid he sought. And that aid was his own.

"My dear Manette, it is the case of an old and prolonged shock, of great acuteness and severity to the affections, the feelings, the-the-as you express itthe mind. The mind. It is the case of a shock under which the sufferer was borne down, one cannot say for how long, because I believe he cannot calculate the time himself, and there are no other means for getting at it. It is the case of a shock from which the sufferer recovered, by a process that he cannot trace himselfbut, unfortunately, there has been"-he paused and took a deep breath-“a slight relapse."

George Eliot, 1860, The mill on the floss

"Dr. Turnbull thought him a deal better this morn- ing," said Mrs Tulliver; "he took more notice, and spoke to me-but he's never known Tom yet-looks at the poor lad as if he was a stranger, though he said something once about Tom and the pony. The doctor says his memory's gone a long way back, and he doesn't know Tom because he's thinking of him when he was little."

Saki, 1914, A holiday task

"It is a curious thing," said the young woman, "that I should be able to tell you the name of those roses without an effort of memory, because if you were to ask me my name I should be utterly unable to give it to you."...

"Yes," answered the lady, "I suppose it is a case of partial loss of memory. I was in the train coming down here; my ticket told me that I had come from Victoria and was bound for this place. I had a couple of fivepound notes and a sovereign on me, no visiting cards or any other means of identification, and no idea as to who I am. I can only hazily recollect that I have a title; I am a Lady Somebody-beyond that my mind is a blank.". .

"Yes, she's the Lady Champion at golf in my part of the world. An awful good sort, and goes about a good deal in Society, but she has an awkward habit of losing her memory every now and then, and gets into all sorts of fixes."

Saki, 1923, The disappearance of Crispina Umberleigh

Her wandering away had been caused by a sudden and complete loss of memory. She usually dressed in the style of a superior kind of charwoman, and it was not so very surprising that she was one, and still less that people should accept her statement and help her to get to work. . . . It was the shock of being patronizingly addressed as "my good woman" by a curate, who was disputing with her where the stove should be placed in a parish concert hall, that led to her sudden restoration of her memory. "I think you forget who you are speaking to," she observed crushingly, which was rather unduly severe, considering she had only just remembered it herself.

G D PERKIN

Regional Neurosciences Centre, Charing Cross Hospital,
London W6 8RF, UK 